\title{
Effectiveness of web-based health education and consultation on health promotion behaviors of adolescents
}

\author{
Sabahat Coşkun ${ }^{1}$, Gülten Güvenç ${ }^{2}$, Hatice Bebiş ${ }^{3}$ \\ (1) Şeyh Edebali University, Faculty of Health Sciences, Bilecik, Turkey \\ (2) University of Health Sciences, Gulhane School of Nursing, Ankara, Turkey \\ (3) Near East University, Lefkoşa, Cyprus
}

Date submitted:

Jun 12, 2019

Date accepted:

Jul 17, 2019

Online publication date:

December 15, 2019

\section{Corresponding Author:}

Sabahat Coşkun

Gulhane Education and

Research Hospital, Education

unit, Ankara, Turkey

sabahatsakar@hotmail.com

Keywords: Health promotion, Health literacy, Online education, Adolescent.

\begin{abstract}
Aims:Adolescence is a critical period for many health-risk behaviours. The purpose of this study was to examine the effectiveness of web-based health education and consultation on health promotion behaviors of adolescence and their e-health literacy.

Methods:This randomized controlled study consisted of 252 adolescence, of whom 120 were in the control group and 132 comprised the intervention group. Students in the intervention group received web based health education and consultation program based on health promotion theory. No procedures were applied to the control group. The results were reevaluated three months after the intervention. Measurements included the e-HEALS: The Health Literacy Scale, Adolescent Lifestyle Questionnaire, Information Assessment Form for the Content of Health Education Program and Satisfaction Evaluation Form.

Results:Results indicated that total Adolescent Lifestyle Questionnaire $(p=0.004)$, e-health literacy $(p=0.001)$ differences were greater in the intervention group than in the control group, and the differences were statistically significant.

Conclusions:Web-based education and consultation demonstrated positive contributions for adolescents'health promotion behaviors and e-health literacy who are the biggest group of internet users, in promoting healthy lifestyle choices.
\end{abstract}

\section{Introduction}

Adolescence is characterized by rapid physical, cognitive, psychological, and social change (1). Many adolescents are at risk for health during this transitional period. According to the Center for Disease Control, risky behaviors for adolescents are smoking, alcohol, violence, unsafe sex, inadequate and unbalanced diet, and insufficient physical activity $(2,3)$. These risky behaviors are avoidable public health problems that cause social problems, mortality, and morbidity in adolescents $(2,4)$. According to Turkey Profile of Adolescent Research 2013; $23 \%$ of the adolescents were behaving aggressively (angry screamers, hit and beat, shattered) when they encountered a problem, adolescents who smoke every day constitute $5 \%$ of the participants, the rate of those who only try alcohol once is $3 \%$, the rate of those who are pessimistic about the future is $11.5 \%, 25 \%$ of the adolescents never got any information about the sex (5). The obesity rate of adolescents in 2014 is 3\% (6).

Adolescents are among the groups that receive much less health care because they have a tendency of not requesting medical care and receiving it compared with individuals from other age groups, as well as because of socio-economical inequalities and their ignorance of the ways of receiving medical care (7). Acquiring and maintaining healthy lifestyle behaviors for adolescents should be the main objective of healthcare professionals (8). Given that adolescents spend most of their time at school, school nurses are the most important members of the health promotion intervention teams. Schools are considered proper places for improving the positive health behaviors of adolescents and their families (9).

In recent years, adolescents have been able to access health information (especially reproductive health, dependence, spirited life, etc.), especially with privacy, by using the internet (10). Internet usage in health education has increased in recent years, because of the low cost, interactive applications, multimedia components, feedback immediately and ease of usage $(11,12)$. Although seemingly very advantageous, the internet is full of risks as not all knowledge presented on the internet is correct, reliable, and of high quality; thus, internet users must be protected from the risks the internet contains and e-health literacy must be improved $(13,14)$. E-health literacy is described as the ability of individuals in applying and evaluating 
health information they acquire from the internet. Individuals with e-health literacy have a higher degree of life quality and display reduced risky than individuals without $(13,15)$.

As a result of wide internet usage, web-based studies aiming to protect and improve public health have been formed $(11,12,16)$. Previous studies reported that web-based health education is effective in adopting healthy eating behavior, increasing physical activity, and improving health (13,17-19). However, most of these studies were about management of chronic diseases or usually about a single field on improving health $(20,21)$. In the literature review, we did not come across web-based intervention studies including all fields of health promotion behaviors of adolescents. Therefore, this study aimed to examine the effectiveness of web-based health education and consultation on health promotion behaviors of adolescents, their e-health literacy, and their information levels.

Our first hypothesis is that adolescents in the intervention (the web-bassed education and consultation) group would report significantly higher level of well-being ( ie, positive life outlook, stress management, spiritual health and health-related quality of life) and health behaviors (ie, health responsibility, nutrition, exercise) at 3-month follow-up compared to the control group. Second, it is expected that participants in the intervention group would report significantly higher level of eHealth literacy and knowledge at 3-month follow-up compared to the control group.

\section{Methods}

\section{Study design}

This study was a randomized controlled trial (RCT) with follow-up assessment after three months. The study has been reported elsewhere (Trial Registration: ClinicalTrials. gov Identifier:NCT03009617;https://clinicaltrials.gov/show/ NCT03009617 ClinicalTrials.gov processed this record on January 04, 2017). Figure 1 depicts a summary of the study design and participant flow based on the CONSORT (Consolidated Standards of Reporting Trials) reporting guidelines (22). The trial was conducted in two public Vocational and Technical high schools in Ankara, Turkey between December 2014 and May 2015.

\section{Ethical Considerations}

This study was carried out after receiving written permission and research approval from the Institutional Ethical Committee and Board and the Provincial National Education Directorate of Ankara. The study was approved by relevant ethics committees (Institutional Ethical Committee; approval number: 32. sessions,12 February 2014 and Provincial National Education Directorate; approval number: 1115, 28 March 2014).Written permission was received from the parents of the students under 18 years of age, and written informed consent was obtained from those over the age of 18.

\section{Participiants}

\section{Sample size calculation}

Power analysis was calculated to determine the study sample. For this purpose, a class of 24 students was chosen as a pilot study from the 10th grade students from the Vocational and Technical High School. In this pilot study, Adolescent Lifestyle Questionnaire (ALQ), e-health literacy scale, and information levels were evaluated pre-intervention. Afterward, the students received education and consultation services for a month, and another valuation was conducted after two weeks. As a result of the pilot study, the pre- and post-differences between the scales were $18.7 \%$ for ALQ, $10 \%$ for e-health literacy, and $45.5 \%$ for information problems. The smallest difference observed was from e-health literacy; the sample size should be 110 to achieve an increase of at least $10 \%$. DSS research site was used to compute the sample. Assuming alpha error $=0.05$, beta error 0.20 , confidence level of $95 \%$, and effect size of $10 \%$ (obtained from pre-application), a total of 220 individuals for both the intervention $(n=110)$ and control $(n=110)$ groups were determined (23). Considering the possibility of the students to leave the research for any reason, the survey sample size was determined as 26411 th grade students for this study and 252 of them completed (intervention; $n=132$, control; $n=$ 120) the study. The sample group to be similar, the students in the 11th grade accounting department were included in the survey (in 2014-2015, 11th grade students $(n=339)$ were eligible to participate). The inclusion criteria were students who volunteered to participate in the study, 9th grade students were not included in the survey because they were just starting school. A pilot study was conducted on 10th grade students. 12th grade students were excluded from the study because they were prepared for the Universe exam.

There were two schools in this study region in terms of similar socio-demographic characteristics. In this study, to prevent receiving information from friends and contamination of the results, two schools were randomly assigned to intervention and control groups. The intervention and control groups were established using a withdrawal method from a sealed opaque envelope. The names of schools were written on papers and placed in two envelopes. The researchers decided that the first chosen school can be assigned as intervention group and the second one as control group. Randomisation was conducted by an independent statistician working at the same university with the researchers and who was not involved in the study.

\section{Procedure}

\section{Development of Educational Content of the Healthy Life Website in Adolescents}

Before the research was implemented, the educational content of the website was prepared. The educational content was created using the literature on the subject within the framework of health responsibility, physical activity, diet, positive view of life, interpersonal relations, stress management, and spiritual health, which are the subcomponents of ALQ. Slogans for each subcomponent of the scale were placed to emphasize the educational content of the website. The subject was supported by examples to increase the sensitivity of adolescents to the issues forclarity and readability. The web pages were designed by two IT specialists, and the educational content was provided by researchers. The opinions of eight experts were considered to evaluate the website and calculate the power analysis of the research. The content validity index was calculated (CV: 1), and pilot implementation was made with 24 students.

A website with management panel via the worldwide web was created in the configuration of the Healthy Life Website in Adolescents. Pages, videos, images, and documents were added, and memberships to the site were approved. Messages and documents could be sent to the members, and messages could be received through this panel. Adolescents were informed through the videos about healthy lifestyle behaviors in the videos menu. The adolescents were able to access the 
website from home/school computers and smart phones.

The Web-based Health Education and Consultation Intervention

First, after the necessary explanations were made to the intervention group about the Introductory Information Form, e-Health Literacy Scale, ALQ, and Information Assessment Form related to the Web-based Health Education Program Content, the students were gathered in a classroom by the researcher and a teacher and asked to fillout the forms in 20-25 minutes under observation. Subsequently, a onehour information meeting was conducted on the website for instructions on how to sign up, how to use the web page, how to use the member panel, how to contact the site manager, and the purpose and contents of the educational program of the website.

In the implementation phase of the intervention, the subjects of health responsibility on the website, physical activity, diet, positive view of life, interpersonal relationships, stress management, and spiritual health were added every two weeks. Previously added issues continued to be published on the site. In this process, consultations were given to the intervention group regarding their questions and requirements on the web environment by reviewing the related literature. Their questions on education were answered through the message menu. Simultaneously, the intervention group was reminded by e-mails and messages at least twice a week for three months to use the educational program.

The website was closed three months later. At the end of the research, each student logged into the website at least seven times and the website was visited 4732 times. During the three months after the closure of the website, the forms applied to the students before the intervention and Satisfaction Evaluation Form for the Web-Based Educational Program toward the Improvement of Adolescent Health were administered by the researcher and a teacher.

\section{Control Group}

The control school applied the usual curriculum during the course of the research. After the necessary explanations about the research in the control group, all the forms that were applied to the intervention group were applied. No intervention was made in the control group during three months, and the same forms were applied again at the end of three months. Immediately after the last test, similar to the intervention group, the students in the control group were ethically ensured to log in the website with their usernames and passwords and benefit from the web-based educational program.

\section{Survey instruments}

\section{Student characteristics:}

This form consists of 23 questions about the demographic characteristics and internet use of the students.

\section{e-HEALS: The Health Literacy Scale}

The e-Health Literacy Scale was developed by Norman and Skinner in 2006 for the determination of traditional literacy, literacy related to health, information retrieval, scientific research, media literacy, and computer literacy. This scale was arranged as a five-point Likert scale consisting of eight items to determine the perceptions of internet use in health issues. The lowest score was 8 and the highest score that could be obtained from the scale was 40 . The high scores received from the scale showed a high level of e-health literacy. Cronbach alpha values were found to be 0.88 in the initial development studies of the scale (24). The Turkish validity and reliability study of the e-Health Literacy Scale was conducted on adolescents by Coskun and Bebis in 2014, and a Cronbach alpha value of 0.78 was reported (25). The Cronbach alpha value in this study was determined to be 0.84 .

\section{Adolescent Lifestyle Questionnaire (ALQ)}

This scale was initially developed in 1997 by Pender and completed by Hendricks, Pender, and Murdaugh in 2006. The scale that was developed based on the health promotion model was a 4-point Likert scale consisting of 44 items and seven subgroups. Its subscales were health responsibility, physical activity, diet, positive view of life, interpersonal relationships, stress management, and spiritual health. In addition to the scores of all items of the scale, the scores for each subscale were also calculated separately; thus, the total scores of the scale and the total scores of each subscale were obtained. A minimum of 44 and a maximum of 176 points could be obtained on the scale. As the points obtained from the scale increased, the levels of positive health behaviors also increased. The Turkish validity and reliability study of ALQ was conducted by Ardıç in 2008. The total internal consistency coefficient of the scale (Cronbach's alpha) was determined to be 0.87 (26). The total internal consistency coefficient was found as 0.89 in this study.

\section{Information Assessment Form for the Content of Health Education Program}

This form was prepared by the researcher in parallel with the information in the content of the web-based health education and consisted of 25 questions. The opinions of eight experts were considered to assess the content validity of the information questions in this study, and the results were evaluated (CVI; $0.96)$. " 1 " point was given for the questions answered correctly and "0" point was given for the wrong answers or for the questions answered as "I don't know."The answers were evaluated over a minimum of " 0 " and maximum of " 25 " points.

\section{Satisfaction Evaluation Form}

This form consisted of 10 questions developed by the researchers to determine the satisfaction of the participants in terms of the structure of the website and the health education programs found in the website. The Satisfaction Evaluation Form was assessed in terms of internal consistency and item analysis, and the Cronbach alpha coefficient was 0.72 .

\section{Analytic strategy}

SPSS 15.0 software package (SPSS, Inc., Chicago, IL, USA) was used to evaluate the data obtained in the study. Descriptive statistics were shown as a number and percentage (\%) of the variables identified by number, as mean \pm standard deviation ( $\pm \mathrm{SD}$ ) for variables determined by measurement, and as minimum-maximum (min-max) values for the median. The compliance of continuous variables with the normal distribution was evaluated in a single-sample Kolmogorov-Smirnov test. To investigate differences, Mann-Whitney $U$ Test was used for the ordinal variables not conforming to the normal distribution, and Pearson Chi-Square test was conducted to analyze categorical variables. Error level was determined as $P=0.05$ for all analyses. 


\section{Results}

\section{Baseline data}

In this study, baseline characteristics of students who completed the baseline student survey are presented in Table 1 and no statistically significant difference was found between the two groups $(p>0.05)$. The baseline variables of both groups were similar (Tablo 1).

The average age of students in the control group was $17.21 \pm$ $0.48(\min =17, \max =19)$, and $53.3 \%$ of them were female. By contrast, the average age of students in the intervention group was $17.23 \pm 0.47(\min =17, \max =19)$ and $41.7 \%$ of them were female. In terms of lifestyle habits, $9.2 \%$ of the control group smoked, $12.5 \%$ of them used alcohol, $9.8 \%$ of the intervention group smoked, and $4.5 \%$ of them used alcohol (Table 1).

The internet usage characteristics of the participants in the control and intervention groups were compared before the intervention (Table 2). Approximately 22.5\% ( $n=27)$ of the control group and $49.2 \%(n=65)$ of the intervention group stated that they did research related to health last week. Mean while, $32.3 \%(n=30)$ of the control group and $70.5 \%(n=93)$ of the intervention group thought that the internet was helpful/very helpful to assist in making decisions about health; $43.3 \%$ of the control group $(n=52)$ and $92.5 \%(n=109)$ of the intervention group stated that access to health resources on the internet was important/very important. A statistically significant difference was found between the groups $(p<.05$; Table 2$)$.

\section{Effect of Web-based Health Education and Consultation}

When the differences of average scores of the control and intervention groups were compared after the intervention (Table 3 ), the differences in $A L Q$ (control group $=-0.68$, experimental group $=8.98, p=.004)$, e-health literacy (control group $=0.10$,

Table 1. Baseline student characteristics by group

\begin{tabular}{|c|c|c|c|c|c|c|}
\hline \multirow{2}{*}{ Characteristics } & \multicolumn{2}{|c|}{ Control $(\mathrm{N}=120)$} & \multicolumn{2}{|c|}{ Intervention $(\mathrm{N}=132)$} & \multirow{2}{*}{$x^{2}$} & \multirow{2}{*}{$p$} \\
\hline & $\mathbf{n}$ & $\%$ & $\mathbf{n}$ & $\%$ & & \\
\hline \multicolumn{7}{|l|}{ Gender } \\
\hline Female & 64 & 53.3 & 55 & 41.7 & \multirow{2}{*}{3.433} & \multirow{2}{*}{0.64} \\
\hline Male & 56 & 46.7 & 77 & 58.3 & & \\
\hline \multicolumn{7}{|l|}{ BMI } \\
\hline Under weight & 45 & 37.5 & 58 & 43.9 & \multirow{3}{*}{1.465} & \multirow{3}{*}{0.481} \\
\hline Normal weight & 61 & 50.8 & 63 & 47.7 & & \\
\hline Over weight & 14 & 11.7 & 11 & 8.3 & & \\
\hline \multicolumn{7}{|l|}{ Family type } \\
\hline Nuclear family & 101 & 84.2 & 111 & 84.1 & \multirow{3}{*}{1.219} & \multirow{3}{*}{0.544} \\
\hline Extended family & 17 & 14.2 & 16 & 12.1 & & \\
\hline Fragmented family & 2 & 1.7 & 5 & 3.8 & & \\
\hline \multicolumn{7}{|l|}{ Income perception } \\
\hline Very good & 5 & 4.2 & 4 & 3.0 & \multirow{3}{*}{0.899} & \multirow{3}{*}{0.638} \\
\hline Good & 109 & 90.8 & 118 & 89.4 & & \\
\hline Average & 6 & 5.0 & 10 & 7.6 & & \\
\hline \multicolumn{7}{|l|}{ Health insurance } \\
\hline Yes & 110 & 91.7 & 120 & 90.9 & \multirow{2}{*}{0.45} & \multirow{2}{*}{0.505} \\
\hline No & 10 & 8.3 & 12 & 9.1 & & \\
\hline \multicolumn{7}{|l|}{ Chronic disease } \\
\hline Yes & 18 & 15.0 & 12 & 9.1 & \multirow{2}{*}{2.093} & \multirow{2}{*}{0.148} \\
\hline No & 102 & 85.0 & 120 & 90.9 & & \\
\hline \multicolumn{7}{|l|}{ Smoking } \\
\hline Yes & 11 & 9.2 & 13 & 9.8 & \multirow{3}{*}{0.038} & \multirow{3}{*}{0.981} \\
\hline No & 101 & 84.2 & 110 & 83.3 & & \\
\hline Quit smoking & 8 & 6.7 & 9 & 6.8 & & \\
\hline \multicolumn{7}{|l|}{ Alcohol use } \\
\hline Yes & 15 & 12.5 & 6 & 4.5 & & \\
\hline No & 102 & 85.0 & 124 & 93.9 & 5.640 & 0.60 \\
\hline Quitalcohol & 3 & 2.5 & 2 & 1.5 & & \\
\hline Regular physical a & & & & & & \\
\hline Yes & 56 & 46.7 & 50 & 37.9 & 1992 & \\
\hline No & 64 & 53.3 & 82 & 62.1 & 1.992 & 0.158 \\
\hline Regular diet & & & & & & \\
\hline Yes & 79 & 65.8 & 74 & 56.1 & 2517 & 0112 \\
\hline No & 41 & 34.2 & 58 & 43.9 & 2.517 & 0.113 \\
\hline
\end{tabular}




\begin{tabular}{|c|c|c|c|c|c|c|}
\hline \multirow[t]{2}{*}{ Variable } & \multicolumn{2}{|c|}{$\begin{array}{l}\text { Control } \\
(\mathrm{N}=120)\end{array}$} & \multicolumn{2}{|c|}{ Intervention $(\mathrm{N}=132)$} & \multirow[t]{2}{*}{$\mathbf{x}^{2}$} & \multirow[t]{2}{*}{$\mathbf{p}$} \\
\hline & $\mathbf{n}$ & $\%$ & $\mathbf{n}$ & $\%$ & & \\
\hline \multicolumn{7}{|c|}{ Doing research for health status on the Internet } \\
\hline Yes & 27 & 22.5 & 65 & 49.2 & \multirow{2}{*}{19.393} & \multirow{2}{*}{0.001} \\
\hline No & 93 & 77.5 & 67 & 50.8 & & \\
\hline \multicolumn{7}{|c|}{ The views on making decisions about health on the Internet } \\
\hline Not at all helpful & 12 & 10.0 & 1 & 0.8 & \multirow{5}{*}{63.208} & \multirow{5}{*}{0.001} \\
\hline Not helpful & 33 & 27.5 & 3 & 2.3 & & \\
\hline Neutral & 41 & 34.2 & 35 & 26.5 & & \\
\hline Helpful & 20.0 & 24.0 & 76 & 57.6 & & \\
\hline Very helpful & 10 & 8.3 & 17 & 12.9 & & \\
\hline \multicolumn{7}{|c|}{ Opinion regarding the Access to health resources on the Internet } \\
\hline Not at all important & 11 & 9.2 & 1 & 0.8 & \multirow{5}{*}{59.346} & \multirow{5}{*}{0.001} \\
\hline Not important & 17 & 14.2 & 4 & 3.0 & & \\
\hline Neutral & 40 & 33.3 & 18 & 13.6 & & \\
\hline Important & 19 & 15.8 & 77 & 58.3 & & \\
\hline Very important & 33 & 27.5 & 32 & 24.2 & & \\
\hline
\end{tabular}

Table 3. The comparison of the differences between the measurements made before and after the intervention in the intervention and control groups ( $\mathrm{N}=252)$

\begin{tabular}{|c|c|c|c|c|c|c|c|}
\hline \multirow{3}{*}{ Variable } & \multicolumn{2}{|c|}{ Control $(\mathrm{N}=120)$} & & \multirow{2}{*}{$\begin{array}{l}\text { Intervention } \\
\text { Pre-test }\end{array}$} & \multirow{2}{*}{$\begin{array}{c}(\mathrm{N}=132) \\
\text { Post test }\end{array}$} & \multirow[b]{3}{*}{ Difference* } & \multirow[b]{3}{*}{$\mathbf{p}^{* *}$} \\
\hline & Pre-test & Post test & & & & & \\
\hline & Mean \pm SD & Mean \pm SD & Difference* & Mean \pm SD & Mean \pm SD & & \\
\hline $\mathrm{ALQ}$ & $121.58 \pm 16.34$ & $120.90 \pm 21.5$ & -0.68 & $118.88 \pm 18.34$ & $127.86 \pm 21.3$ & 8.98 & 0.004 \\
\hline Health responsibility & $16.23 \pm 3.69$ & $16.74 \pm 3.70$ & 0.51 & $15.78 \pm 3.56$ & $17.75 \pm 4.24$ & 1.97 & 0.022 \\
\hline Physical activity & $14.70 \pm 4.03$ & $15.74 \pm 4.12$ & 1.04 & $13.96 \pm 4.44$ & $16.18 \pm 4.20$ & 2.22 & 0.063 \\
\hline Diet & $18.67 \pm 3.22$ & $18.47 \pm 3.69$ & -0.20 & $18.81 \pm 3.78$ & $20.24 \pm 4.03$ & 1.43 & 0.019 \\
\hline Positive view of life & $19.07 \pm 3.29$ & $18.38 \pm 3.87$ & -0.69 & $18.99 \pm 3.44$ & $19.34 \pm 3.56$ & 0.35 & 0.143 \\
\hline $\begin{array}{l}\text { Interpersonal rela- } \\
\text { tions }\end{array}$ & $18.60 \pm 3.13$ & $18.10 \pm 3.62$ & -0.50 & $18.04 \pm 3.30$ & $18.62 \pm 3.44$ & 0.58 & 0.035 \\
\hline Stress management & $17.66 \pm 3.68$ & $17.51 \pm 3.44$ & -0.15 & $17.31 \pm 3.09$ & $18.42 \pm 3.36$ & 1.11 & 0.093 \\
\hline Spiritual health & $16.62 \pm 3.28$ & $15.60 \pm 3.42$ & -1.56 & $15.96 \pm 3.28$ & $17.20 \pm 3.32$ & 1.24 & 0.001 \\
\hline E-health literacy & $27.27 \pm 6.65$ & $27.37 \pm 6.02$ & 0.10 & $26.99 \pm 5.58$ & $30.55 \pm 6.92$ & 3.56 & 0.001 \\
\hline Level of knowledge & $12.70 \pm 4.62$ & $11.45 \pm 5.46$ & -1.25 & $13.81 \pm 3.40$ & $17.08 \pm 4.00$ & 3.27 & 0.001 \\
\hline
\end{tabular}

experimental group $=3.56, p=.001$ ), and level of knowledge (control group $=-1.25$, experimental group $=3.27, p=$ .001) were statistically significantly higher in the intervention group than in the control group $(p<.05)$. In addition, after the intervention, there was a moderate $(r=0.411)$ and significant $(p<.001)$ correlation between mean ALQ and mean e-health literacy scores.

The majority of the adolescents in the intervention group stated that the structure of the website was an appropriate method of education for health promotion. Moreover, they found that the content of the educational program was adequate, clear, and understandable in terms of knowledge, and they learned new and useful information. In addition, they also stated that they wanted the continuation of web-supported programs; the videos, images, and shapes were designed properly on web pages; the website and desired information were easy to access; and they easily established communication with the researcher. 


\section{Discussion}

Adolescents can access information easily because of the internet, conduct research, and consider the internet as a source of support that develops their skills such as problemsolving, creativity, and critical thinking (27). In our study, half of the adolescents who were provided with web-based intervention stated that they conducted research about health on the internet. Almost all of them stated that the health information they obtained was important, and two-thirds of them found it helpful.

Web-based health education and consultation increased the knowledge scores of intervention group statistically. Similarly, previous studies indicated that web-based education increases the level of knowledge of the participants $(18,28)$. However, a study reported that, although adolescents frequently used information technology, they had difficulty in using and understanding the on-line health information (29). False, misleading, and low-quality information on the internet can cause various health problems in this group, which uses the internet quite frequently (14). This situation reveals the importance of e-health literacy and the presence of reliable sites directed by health employees so that adolescents can access the true information. Individuals with high E-health literacy are able to understand the information that they find, differentiate the quality of health websites, evaluate the truth of the information (13). In the current study, after the intervention, the mean E-health literacy scores in the intervention group were significantly higher than those in the control group. Studies regarding the e-health literacy levels of adolescents and which factors develop e-health literacy are few. One study reported that the E-health literacy levels of students conspicuously increased in students as a result of the education they gave to increase E-health literacy in the subjects of balanced diet, intake of nutrients and physical activity (15). Other study revealed that individuals with a high level of E-health literacy are more inclined to use the internet to find answers to healthrelated problems (30). In addition, this study found that after the intervention a significant positive relationship between E-health literacy and ALQ scores $(r=0.411 ; p=0.001)$. According to results of some studies, E-health literacy might affect individuals' health behaviors. For example; use of health information on the internet can affect personal exercise habitude and eating/ food consumption habitude that individuals with high E-health literacy may adopt more positive health behaviors $(30,31)$

In this study, the average ALQ scores of the intervention group were significantly higher than those of the control group after the training and consultation programs were applied for three months. No study regarding all the aspects of healthy lifestyle behaviors in adolescents through the web was encountered in the literature; however, studies that focused on one or a few areas of healthy lifestyle behaviors were found $(17,19)$. These studies similarly obtained positive results, such as development of communication skills, stress reduction, healthy diet, and increase in physical activity.

In this study, after the intervention the average score of the health responsibility subscale of ALQ was found significantly higher in the intervention group. Although no studies on adolescents were encountered, studies that focused on adults reported an increase in health responsibility (32). No difference was found in the average scores of the physical activity subscale between intervention and control groups. Given that awareness may have been raised for physical activity in the control group, as well as exposure to outdoor air was suitable in the period of study, this situation could be attributed to the increase in physical activity of the students in both groups. A previous study reported an increase in physical activity of the students at schools but no increase in daily life (33). A study also reported positive changes in adolescents' beliefs and selfefficacy regarding physical activity (34).

In our study, web-based education was considered effective in increasing the knowledge and awareness of healthy diet, but further studies are necessary to evaluate the long term effects. Intervention studies on the diet of adolescents were reported different results. In a systematic review, computersupported obesity related education programs were found to show small changes in the results of diet, physical activity, body mass index (35). In a web-supported randomized controlled study a significant drop in the waist-to-hip ratio and increases in vegetable and fruit intake, and knowledge about physical activity and nutrition (36). Considering the positive effects of web-based education and counseling on adolescent nutrition in our study, web-based nutrition education recommended in interventions to large sample groups because of its low cost, taking short time, and ability to reach large groups.

The difference between the mean scores of the positive view of life subscale was found to be statistically significant between two groups. According to the data of Turkish Statistical Institute in our country in $2013,83.9 \%$ of the young people stated that they were hopeful for the future and $65.1 \%$ of them said they were happy (6). However, another study found that many young people are pessimistic (37).

This study, the difference between the average scores of the interpersonal relationship subscale was also statistically significant. The literature revealed that the interventions performed for the development of interpersonal relationships in adolescents are effective, but the studies were not carried out over the web (38).

In the current study the intervention did not effect on the stress management subscale scores. In the literature, webassisted stress management interventions were found to be effective in adult individuals (39). However, no studies on adolescents were encountered. An increase in the average score of stress management was observed in our study, but individual interventions and qualitative studies are needed because the intervention did not show the desired effect.

The intervention also increased significantly mean scores of the spiritual health subscale of intervention group. In the literature, meeting the spiritual needs of individuals showed that they can cope with stressful, difficult, and demanding situations and they feel better (40). In our study, awareness of spiritual health was given to adolescents in the intervention group, and their knowledge regarding this issue increased.

The majority of the adolescents in the intervention group stated that the structure of the website was an appropriate method of education for health promotion; the content of the educational program was adequate, clear, and understandable in terms of knowledge; they learned new and useful information; and they felt valuable.

\section{Limitation and Generalisability}

An important strength of this study is the randomized 
controlled design and focusing many aspects of healthy lifestyle behaviors in adolescents through the web-based education and consultation. Another strength is that to prevent receiving information from friends and contamination of the results the intervention and control groups were chosen from different schools. However, this study has some limitations. The effects of intervention were re-evaluated three months after the intervention. The long-term effects of the research could not be determined. The effects of web-based education and consultation programs on long-term healthy lifestyle and behavioral changes that improve health can be evaluated in future studies. Research results could not be generalized for all adolescents in our country because this study was conducted in designated high schools. Additionally, a reliance on participant self-reported data, which may negatively affect the validity of responses.

\section{Conclusion}

Web-based health education is independent, convenient in access, cost saving, easily updated contents and with emerging technologies it can be made more effective. Through the training and consultation program conducted via the web for "health promotion," which is an important part of a school's healthcare, interactive communication methods between school nurses and students were provided. The results of this study showed that web-based education was effective in increasing knowledge, E-health literacy and improving attitudes of adolescents' healthy lifestyles (healthy diet, health responsibility, interpersonal relationships, and spiritual health) in Turkey. The most requested consultancy topics by students were healthy eating, nutrition during menstruation, nutritional supplements, and balancing ideal weight. Since there is no web-based intervention studies including all fields of health promotion behaviors in Turkey, planning similar studies is suggested. Further randomized control studies are also recommended with different populations and in other settings.

\section{Acknowledgments}

Study design: SC, HB, data collection: SC, analysis: SC, GG and manuscript preparation: SC, GG, and HB.

\section{Conflict of Interest}

The authors have no conflict of interest.

\section{References}

1. Sanders RA. Adolescent psychosocial, social, and cognitive development. Pediatrics in Review. 2013;34(8):354-359.

2. Bannink R, Broeren S, Joosten-van Zwanenburg E, et al. Effectiveness of a Web-Based Tailored Intervention (E-health4Uth) and Consultation to Promote Adolescents' Health: Randomized Controlled Trial. J Med Internet Res. 2014;16(5):e143-e165.

3. Kann L, Kinchen S, Shanklin SL, et al. Youth risk behavior surveillance - United States, 2013. MMWR. 2014;63(4):1-47.

4. Brener ND, Kann L, Kinchen SA, et al. Methodology of the youth risk behavior surveillance system 2013. MMWR. 2014;62(1):1-20.

5. Turkey Profile of Adolescent Research 2013. https:// ailetoplum.aile.gov.tr/duyurular/turkey-ergen-profili- arastirmasi-tepe-2013. Accessed November, 2017.

6. Turkish Statistical Institute (TUIK), Youth in Statistics 2015. http://www.tuik.gov.tr/PreHaberBultenleri. do?id=21517. Accessed March 16, 2017.

7. Pekcan H. Adolescent Health. In: Ç Güler, L Akın, eds. Basics of Public Health. Ankara, Hacetepe University Press; 2012:486-538.

8. Musavian AS, Pasha A, Rahebi SM, et al. Health promoting behaviors among adolescents: a crosssectional study. Nurs Midwifery Stud. 2014;3(1):1-7.

9. Bebis H, Akpunar D, Özdemir S, et al. Assessment of health promotion behavior of adolescents in a high school. Gulhane Med J. 2015;57(2):129-135.

10. Hamann C, Schultze-Lutter F, Tarokh L. Web-based assessment of mental well-being in early adolescence: a reliability study. J Med Internet Res. 2016;18(6): e138-e148.

11. Aslan D, Yavuz Cl. Use of web based research in public health. Turk J Public Health. 2013;11(2):104-110.

12. Özer Ö, Şantaş F, Budak F. A study of health web sites' usage level: a case application. Gumushane University E-Journal of Faculty of Communication. 2012;1(4):128140.

13. Hsu W, Chiang C, Yang S. The effect of Individual factors on health behaviors among college students: the mediating effects of ehealth literacy. J Med Internet Res. 2014;16(12):e287-e303.

14. Skinner H, Biscope S, Poland B, et al. How adolescents use technology for health information: Implications for health professionals from focus group studies. J Med Internet Res. 2003;5(4):e32-e42.

15. Paek HJ, Hove T. Social cognitive factors and perceived social influences that improve adolescent ehealth literacy. Health Commun. 2012;27(8):727-737.

16. Özbıçakçı Ş. School nursing and computer based health education. DEUHYO ED. 2014;7(3):246-251.

17. Bastani F, Hashem S. Effects of a web-based lifestyle education on general health and severity of the symptoms of premenstrual syndrome (PMS) among female students: a randomized controlled trial. Procedia - Social and Behavioral Sciences. 2012;46:3356-3362. doi: 10.1016/j.sbspro.2012.06.066

18. Cousineau TM, Franko DL, Ciccazzo M, et al. Webbased nutrition education for college students: Is it feasible? Eval Program Plann. 2006;29(1):23-33.

19. Schwinn TM, Schinke S, Fang L, et al. A web-based, health promotion program for adolescent girls and their mothers who reside in public housing. Addic Behav. 2014;39(4):757-760.

20. Demir Y, Gözüm S. New approaches in health education; web-based health education. DEUHYO ED. 2011;4(4):196-203.

21. Kim J, Lee S, Kim JH. Effects of a web-based stroke education program on recurrence prevention behaviors among stroke patients: a pilot study. Health Education 
Research. 2013;28(3):488-501.

22. Boutron I, Moher D, Altman DG, et al. Extending the CONSORT statement to randomized trials of nonpharmacologic treatment: explanation and elaboration. Annals of Internal Medicine. 2008;148(4):295-309.

23. Sample Size Calculators. https://www.dssresearch. $\mathrm{com} / \mathrm{knowledgecenter/toolkitcalculators/}$ samplesizecalculators.aspx. Accessed December 5, 2015.

24. Norman CD, Skinner HA. eHEALS: the Ehealth Literacy Scale. J Med Internet Res. 2006;8(4):e27-e38.

25. Coskun S, Bebis $H$. Psychometric evaluation of a Turkish version of the e-health literacy scale (e-heals) in adolescent. Gulhane Med J. 2015;57(4):378-384.

26. Çövener Ç. Health Promotion Model. In: A Ocakçı, Ş Alpar, eds. Concepts, Theories and Models Samples in Nursing. İstanbul, İstanbul Publication; 2013:200-215.

27. Esen E, Siyez MD. An investigation of psycho-social variables in predicting internet addiction among adolescents. Turkish Psychological Counseling and Guidance Journal. 2011;4(36):127-138.

28. Huang MZ, Kuo SC, Avery MD, et al. Evaluating effects of a prenatal web-based breastfeeding education programme in Taiwan. J Clin Nurs, 2007;16(8):15711579.

29. Gray NJ, Klein JD, Noyce PR, et al. The Internet: a window on adolescent health literacy. J Adolesc Health. 2005;37(3):243-250.

30. Chiang C, Yang S. The Effect of individual factors on health behaviors among college students: the mediating effects of ehealth literacy. J Med Internet Res. 2014;16(12):e287-e303.

31. Mitsutake S, Shibata A, Ishii K, et al. Association of eHealth literacy with colorectal cancer knowledge and screening practice among internet users in Japan. J Med Internet Res. 2012;14(6):e153-e167.

32. Çapık C, Gözüm S. The effect of web-assisted education and reminders on health belief, level of knowledge and early diagnosis behaviors regarding prostate cancer screening. Eur J Oncol Nurs. 2011;16(1):71-77.

33. Haerens L, Deforche B, Vandelanotte C, et al. Acceptability, feasibility and effectiveness of a computertailored physical activity intervention in adolescents. Patient Educ Couns. 2007;66(3):303-310.

34. Marks JT, Campbell MK, Ward DS, et al. Comparison of Web and Print Media for Physical Activity Promotion among Adolescent Girls. J Adolesc Health. 2006;39(1):96-104.

35. Ajie WN, Chapman-Novakofski KM. Impact of Computer-Mediated, obesity-related nutrition education interventions for adolescents: a systematic review. J Adolesc Health. 2014;54(6):631-645.

36. Chen JL, Weiss S, Heyman MB, et al. The efficacy of the web-based childhood obesity prevention program in Chinese American adolescents. J Adolesc Health.
2011;49(2):148-154.

37. Özmen D, Dündar PE, ÇetinkayaAÇ, et al. Hopelessness and factors affecting hopelessness in high school students. Anadolu Psikiyatri Derg. 2008;9(1):8-15.

38. Bedel A, Arı R. Interpersonal problem solving skills training's effect on the adolescents' living in orpanhages constructive problem-solving and the level of trait anger. Pegem Journal of Education and Instruction. 2011;1(4):1-10.

39. Heber E, Ebert DD, Lehr D, et al. Efficacy and costeffectiveness of a web-based and mobile stressmanagement intervention for employees: design of a randomized controlled trial. BMC Public Health. 2013;15(13):1-12.

40. Uğurlu SE, Başbakkal Z. Spiritual care requirements of the mothers of the hospitalized children in intensive care units. Journal of the Turkish Society of Intensive Care. 2013;11(1):17-24. 